\title{
Motility of the antroduodenum in healthy and gastroparetics characterized by wireless motility capsule
}

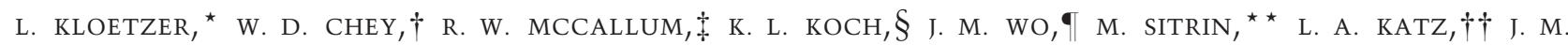

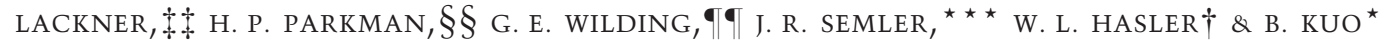

${ }^{\star}$ Gastroenterology Unit, Massachusetts General Hospital, Harvard Medical School, Boston, MA, USA

$\dagger$ Division of Gastroenterology, Department of Internal Medicine, University of Michigan, Ann Arbor, MI, USA

†Center for Gastrointestinal Nerve \& Muscle Function \& GI Motility, University of Kansas Medical Center, Kansas City, KS, USA

$\S$ Gastroenterology, Wake Forest University Baptist Medical Center, Winston Salem, NC, USA

-Division of Gastroenterology/Hepatology, University of Louisville, Louisville, KY, USA

${ }^{\star \star}$ Division of Gastroenterology, Hepatology and Nutrition, Department of Medicine, Western New York VA Medical Center, SUNY at Buffalo, Buffalo, NY, USA

††Department of Medicine, University at Buffalo School of Medicine, SUNY, Buffalo, NY, USA

†Division of Gastroenterology, Hepatology, and Nutrition, Department of Medicine, Behavioral Medicine Clinic, University at Buffalo School of Medicine, SUNY, Buffalo, NY, USA

$\S \S$ Gastroenterology Section, Department of Medicine, Temple University School of Medicine, Philadelphia, PA, USA

- Department of Biostatistics, SUNY at Buffalo, Buffalo, NY, USA

${ }^{\star \star \star}$ The Smart Pill Corporation, Buffalo, NY, USA

\begin{abstract}
Background The wireless motility capsule (WMC) measures intraluminal $\mathrm{pH}$ and pressure, and records transit time and contractile activity throughout the gastrointestinal tract. Our hypothesis is that WMC can differentiate antroduodenal pressure profiles between healthy people and patients with upper gut motility dysfunctions. This study aims to analyze differences in the phasic pressure profiles of the stomach and small intestine in healthy and gastroparetic subjects. Methods Data from 71 healthy and 42 gastroparetic subjects were analyzed. The number of contractions (Ct), area under the pressure curve and motility index $\left(M I=L n\left(C t{ }^{*}\right.\right.$ sum amplitudes +1)) were analyzed for 60 min before gastric emptying of the capsule (GET), (gastric window) and after GET (small bowel window) and results between groups were compared with the Wilcoxon rank sum test.
\end{abstract}

\section{Address for correspondence}

Braden Kuo, MD, Gastroenterology Unit, Blake 4, Massachusetts General Hospital, 55 Fruit St., Boston, MA 02114, USA. Tel: 617-726-2132; fax: 617-724-1091;

e-mail: bkuo@partners.org

Clinical Trial Registry: NCT 00128284

Received: 22 June 2009

Accepted for publication: 8 December 2009
Key Results Significant differences were observed between healthy and gastroparetic subjects for Ct and MI $(P<0.05)$. Median values of the motility parameters in gastric window were $C t=72, M I=11.83$ for healthy and $C t=47, M I=11.12$ for gastroparetics. In the small bowel, median values were $C t=144.5$, $M I=12.78$ for healthy and $C t=93, M I=12.12$ for gastroparetics. Diabetic subjects with gastroparesis showed significantly lower Ct and MI compared with healthy subjects in both gastric and small bowel windows while idiopathic gastroparetic subjects did not show significant differences. Conclusions et Inferences The WMC is able to differentiate between healthy and gastroparetic subjects based on gastric and small bowel motility profiles.

Keywords ambulatory capsule, gastroparesis, manometry.

\section{INTRODUCTION}

Gastroparesis is characterized by symptoms and objective delay in gastric emptying in the absence of a mechanical obstruction. Normal gastric motility and gastric emptying require an integrated, coordinated function of the sympathetic, parasympathetic, and enteric nervous systems and the gastrointestinal (GI) smooth muscle cells. Disturbances of neural or 
muscular components and Interstitial Cells of Cajal can alter gastric function, and gastric emptying. ${ }^{1}$

Clinically gastroparesis manifests itself as non-specific symptoms such as early satiety, bloating, nausea, heartburn, anorexia, vomiting, abdominal pain, and weight loss and is most commonly associated with diabetes mellitus or an idiopathic etiology. ${ }^{2}$ As the symptoms of gastroparesis are non-specific, measurement of gastric motility including gastric transit and pressure profiles are useful in defining the types of functional abnormalities associated with gastroparesis.

Gastric emptying scintigraphy (GES) is the most commonly utilized means of assessing gastric transit although the need for radioisotopes and the lack of standardization of test methods has limited the usefulness of this technique in clinical practice. Gastric and duodenal pressure profiles obtained with multiple pressure sensors placed across the gastroduodenal junction have been used to identify neuropathic and myopathic abnormalities of gastroparesis, such as a reduction in the number and amplitude of contractions respectively. ${ }^{3,4}$ Abnormalities in frequency and amplitude of contractions have also been shown with a number of other conditions including peptic ulcer disease, functional dyspepsia, celiac disease and other forms of malabsorption. ${ }^{5-8}$ While helpful and informative to clinical evaluation, current manometric tests are expensive, difficult to perform, involve radiation exposure for correct placement and are difficult for patients to tolerate. ${ }^{9}$ Further, manometric studies are available at just a few tertiary centers. ${ }^{10}$

We performed an analysis of pressure patterns in healthy volunteers and patients with gastroparesis using data from a prior study which assessed gastric emptying by wireless motility capsule (WMC). ${ }^{11}$ While there is literature to suggest that emptying of the WMC correlates with solid phase emptying measured by scintigraphy, specifics regarding the pressure data recorded by this technology are lacking. ${ }^{11}$ We focused on the pressure profiles in the distal stomach and proximal small intestine in healthy subjects and gastroparetic patients. The aim of our analysis was to assess the ability of a WMC, a freely moving nontethered pressure sensing device, to differentiate the phasic pressures in the stomach and proximal small intestine between healthy subjects and gastroparetic patients. We sought further to investigate: (i) whether gastroparetics can be stratified according to gastric emptying time (GET) and pressure profiles, (ii) if pressure profile differences exist between diabetic and idiopathic gastroparetics, and (iii) if pressure profile abnormalities occur in regions other than the stomach in gastroparesis.

\section{METHODS}

\section{Subject enrollment}

The multicenter study was conducted at seven academic centers from March 2005 to October 2007, and the Institutional Review Board of each participating center approved the study protocol (Clinical trial registry\# NCT00128284). Subjects entered the study after the nature and purpose were explained and after they granted written informed consent. Two groups were recruited: healthy subjects and subjects with a history of gastroparesis. $^{11}$

\section{Inclusion/exclusion criteria}

The healthy subjects (males and females) were between 18 and 65 years of age with no GI disease as screened by the Mayo Disease Screening Questionnaire. ${ }^{12}$

Male and female gastroparetic subjects between 18 and 65 years of age who had been previously diagnosed as gastroparetic with both symptoms of gastroparesis including nausea, vomiting, postprandial fullness, early satiety, epigastric pain or discomfort for at least 6 months and a documented abnormal scintigraphy determined by local standards where the patient was originally tested within the past 2 years were enrolled. ${ }^{11}$ The gastroparetic group included both diabetic and idiopathic patients.

Subjects with previous gastro-esophageal or other GI surgery were excluded. Subjects with severe gastric dysmotilities who had severely delayed gastric scintigraphic studies $>50 \%$ retention at $4 \mathrm{~h}$ ) and/or history of gastric bezoars were also excluded. Medications that can affect GI transit parameters or may cause delayed gastric emptying were stopped at least 3 days prior to WMC ingestion and during the study.

\section{Pressure and $\mathrm{pH}$ monitoring system}

$\mathrm{pH}$ and pressure data were obtained with the WMC system (The Smart Pill Corporation, Buffalo, NY, USA). The capsule houses sensors for $\mathrm{pH}$, temperature, and pressure and transmits the data to a receiver worn by the subject during ambulatory monitoring. The WMC is $13 \mathrm{~mm}$ across and $\times 26 \mathrm{~mm}$ long. The capsule and receiver have battery lives rated for 5 days. $\mathrm{pH}$ is accurate to within $0.5 \mathrm{U}$ and pressure is accurate to $\pm 5 \mathrm{mmHg}$ below $100 \mathrm{mmHg}$. After completion of the test, data were downloaded to a computer from the data receiver through a docking station and was analyzed using pressure analysis software (GIMS 1.8; The Smart Pill Corporation).

\section{Wireless motility capsule test}

Subjects swallowed the WMC with $50 \mathrm{~cm}^{3}$ of water followed by ingestion of a standard egg meal with a total caloric value of $255 \mathrm{kcal}\left(72 \%\right.$ carbohydrate, $24 \%$ protein, $2 \%$ fat, and $2 \%$ fiber). ${ }^{13}$ Meals of similar caloric content have been shown to induce postprandial patterns of contraction. ${ }^{14}$ Six hours after capsule ingestion, subjects consumed $250 \mathrm{~mL}$ Ensure ${ }^{\circledR}$ and water was taken ad libitum. Approximately $8 \mathrm{~h}$ after capsule ingestion subjects left the study center with the data receiver to enable continued data acquisition from the capsule. At $48-120 \mathrm{~h}$ postingestion, subjects returned with the data receiver and diary. Capsule exit was confirmed for each subject by plain abdominal radiograph (KUB) unless the subject retrieved and returned the capsule. $^{15-17}$ 


\section{Assessment of gastroduodenal motility}

Motility parameters were compared between healthy and gastroparetic subjects in the stomach and small bowel during the last hour of WMC's gastric location and the first hour in the small bowel. Pressure profiles in these regions were analyzed if $\geq 85 \%$ of the pressure data was available. The transition from stomach to small bowel was marked by an abrupt $\mathrm{pH}$ rise (>3 $\mathrm{pH}$ units) from gastric baseline to a $\mathrm{pH}$ greater than $4 .^{18-20}$ This $\mathrm{pH}$ change marked the end of the gastric pressure analysis window and the beginning of the small bowel pressure analysis window. The number of contractions $(\mathrm{Ct})$, area under the pressure curve (AUC), and motility index defined as: $\mathrm{MI}=\mathrm{Ln}$ (sum of pressure amplitudes $\times$ number of contractions +1$)^{21}$ were characterized for each $1 \mathrm{~h}$ time window. Pressure peaks exceeding $10 \mathrm{mmHg}$ but less than $300 \mathrm{mmHg}$ were included in the analyses. ${ }^{22-24}$ The AUC pressure was computed as the total area under the curve for the window chosen. Gastric emptying time is defined as the duration of time from WMC ingestion to entry into the duodenum.

\section{Statistical analysis}

To assess statistical differences between groups, the Wilcoxon rank sum test was used to compare the motility parameters (Ct, AUC, and MI) for healthy and gastroparetic subjects. The motility parameters of diabetic and idiopathic gastroparetics were also compared with healthy subjects in a post hoc analysis. Motility parameters were also compared between healthy subjects and the group of excessively delayed gastroparetic subjects (GET $>12 \mathrm{~h}$ ). Reported $P$-values were obtained from the permutation distributions of the test statistics. A nominal significance level of 0.05 was used in all testing.

\section{RESULTS}

\section{Study subjects and demographics}

Data from 113 subjects [ 71 healthy subjects: 28 female, mean age (range) 32 years (19-57)] and 42 gastroparetics [34 female, mean age 43 years (19-66)] met the inclusion criteria of this analysis. Sixteen of the gastroparetic subjects were diabetic ( 12 female) and 26 subjects had gastroparesis of idiopathic origin (22 female). Twelve subjects (six healthy and six gastroparetic) were excluded from the study due to incomplete pressure data resulting from subjects' failure to wear the receiver at all times.

\section{Wireless motility capsule tracings}

Graphic results of tests were displayed with WMC software (MotiliGI 1.3.1; The Smart Pill Corporation). Fig. 1A exemplifies the WMC tracing of a healthy subject with pressure, $\mathrm{pH}$ and temperature recordings in the two time windows of interest, $60 \mathrm{~min}$ before and after GET. Fig. 1B represents a tracing of a gastroparetic patient. The tracings illustrate the differences in gastric transit (GET) and frequency of contractions found in the two groups.
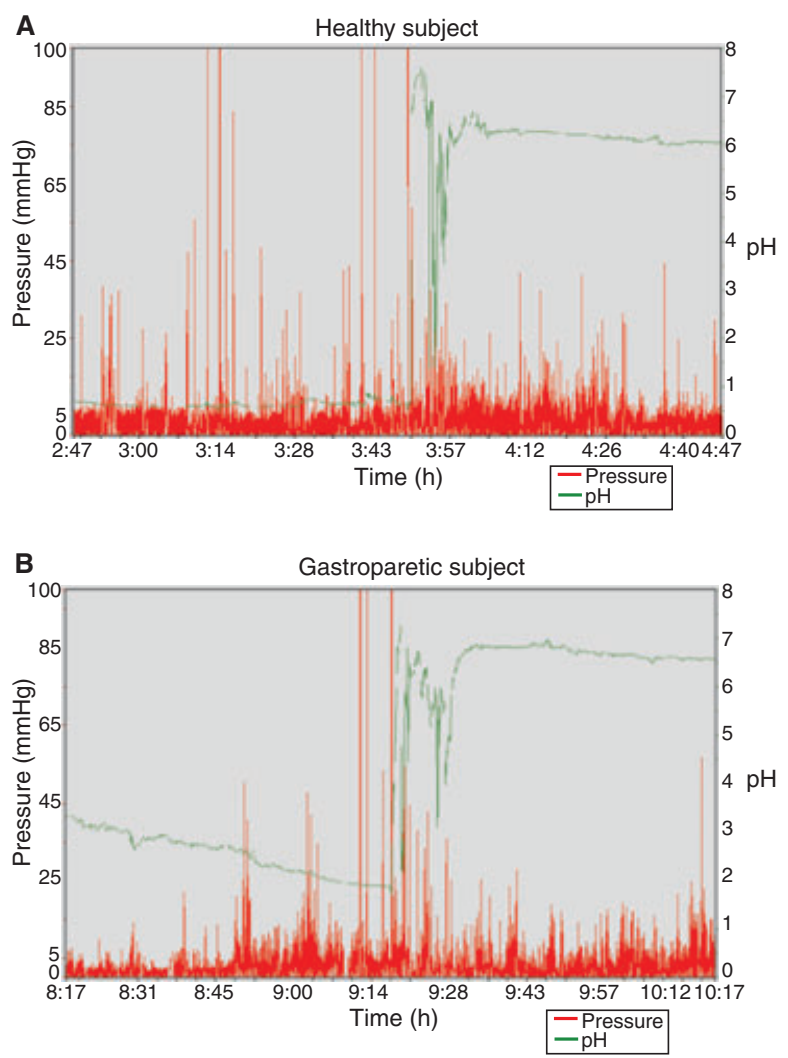

Figure $1 \mathrm{pH}$ and pressure recordings for $1 \mathrm{~h}$ before and after gastric emptying time (GET), defined as an abrupt rise in the $\mathrm{pH}$ profile (>3 units). The red tracing and axis on the left shows pressure profile as recorded by WMC. The green tracing and axis on the right shows the $\mathrm{pH}$ tracing with the abrupt rise of $\mathrm{pH}$ at GET. (A) Tracings for a healthy subject with GET $<5 \mathrm{~h}$ and normal manometric patterns. (B) Tracings for a gastroparetic diabetic with GET $>5 \mathrm{~h}$ and lower amplitude and frequency of contractions.

\section{Characterization of gastric and small bowel motility}

The primary analyses compared pressure profiles in the healthy subjects to the patients with gastroparesis. Median and interquartile range (IQR 25-75\%) values for each pressure parameter for gastric and small bowel analyses are provided in Table 1. Pressure parameters $(\mathrm{Ct}, \mathrm{AUC}$, and $\mathrm{MI})$ in the $1 \mathrm{~h}$ gastric and small bowel analyses windows were statistically different for $\mathrm{Ct}$ $(P<0.05)$ and MI $(P<0.05)$ between healthy and gastroparetic subjects. There was no statistical difference for AUC in either analyses window. Normal females $\left(84 \mathrm{Ct} \mathrm{h}^{-1}\right)$ had higher rates of contraction compared to normal males $\left(69 \mathrm{Ct} \mathrm{h}^{-1}\right)$ in the stomach $(P=0.01)$ and also higher rates in the proximal small bowel [females $146 \mathrm{Ct} \mathrm{h}^{-1}$ vs males $139 \mathrm{Ct} \mathrm{h}^{-1}$, $(P=0.02)]$. The effect of age on pressure profiles in healthy subjects was assessed by division of the healthy subjects into three age groups. Normal subjects 
Table 1 Median values and interquartile range (25-75\%) of motility parameters for healthy vs gastroparetic subjects

\begin{tabular}{|c|c|c|c|c|c|c|}
\hline & \multicolumn{3}{|c|}{ Gastric window } & \multicolumn{3}{|c|}{ Small bowel window } \\
\hline & $\mathrm{Ct} \mathrm{h}^{-1}$ & $\mathrm{AUC}\left(\mathrm{mmHg} \mathrm{s}^{-1}\right)$ & MI & $\mathrm{Ct} \mathrm{h}^{-1}$ & $\mathrm{AUC}\left(\mathrm{mmHg} \mathrm{s}^{-1}\right)$ & MI \\
\hline Normal subjects, $n=71$ & $72(45,110)$ & $4789(3091,6933)$ & $11.83(11.01,12.76)$ & $145(88,199)$ & $5182(2791,7538)$ & $12.78(11.71,13.48)$ \\
\hline $\begin{array}{l}\text { Patients with } \\
\text { gastroparesis, } n=42\end{array}$ & $47(24,80)$ & $4041(1942,5913)$ & $11.12(10.01,12.26)$ & $93(53,161)$ & $4736(2426,8350)$ & $12.12(10.96,13.13)$ \\
\hline$P$-value & 0.01 & 0.14 & 0.02 & 0.02 & 0.68 & 0.04 \\
\hline
\end{tabular}

$\mathrm{Ct}$, number of contractions; MI, motility index; AUC, area under the pressure curve.

$>41$ years had a higher rate of contractions in the proximal small bowel $\left(187 \mathrm{Ct} \mathrm{h}^{-1}\right)$ compared to subjects ages $<27$ years $\left(117 \mathrm{Ct} \mathrm{h}^{-1}\right)(P=0.02)$ but they were not significantly different from subjects $\geq 27$ and $\leq 41$. There was not enough power to examine differences between gender and age in the gastroparetic population. Significant differences in median values for contraction frequency and MI persisted after adjusting for these gender and age differences between the healthy and gastroparetic subjects.

The fifth percentile of healthy subjects had $\leq 29 \mathrm{Ct} \mathrm{h}^{-1}$ for the gastric window and $36 \mathrm{Ct} \mathrm{h}^{-1}$ for the small bowel window. The corresponding fifth percentile values for MI were 9.82 and 10.57 respectively and AUC were 1358 and 1456 respectively. Thirty-three percent of the overall gastroparetic patients had gastric contraction frequencies below the fifth percentile of the normal range. Forty percent of the diabetic and $28 \%$ of the idiopathic subgroups were below the fifth percentile of the normal population (Table 2). For gastroparetic patients who had a GET $>5$ h, $52 \%$ had abnormal low gastric contractility. Sixty percent of the diabetics and $46 \%$ of the idiopathic subgroups in this population had abnormal gastric contraction frequencies.

The subgroup of gastroparetic subjects with diabetes (16 subjects) had significantly lower Ct and MI from that of healthy subjects in both gastric and small bowel analyses windows $(P<0.05)$ while differences in pressure profiles of idiopathic etiologies (26 subjects) showed a trend towards significant differences only in the gastric window (Table 3). Pressure profiles were not significantly different between diabetic and idiopathic subgroups.

\begin{tabular}{|c|c|c|c|c|c|c|}
\hline & \multicolumn{3}{|c|}{$\begin{array}{l}\text { Gastric motor impairment } \\
<5 \text { th percentile of normals }\end{array}$} & \multicolumn{3}{|c|}{$\begin{array}{l}\text { Small bowel motor impairment } \\
<5 \text { th percentile of normals }\end{array}$} \\
\hline & $\begin{array}{l}\mathrm{Ct} \\
(<29 / \mathrm{h})\end{array}$ & $\begin{array}{l}\text { MI } \\
(<9.82)\end{array}$ & $\begin{array}{l}\text { AUC } \\
\left(<1358 \mathrm{~mm} \mathrm{~h}^{-1}\right)\end{array}$ & $\begin{array}{l}\mathrm{Ct} \\
(<36 / \mathrm{h})\end{array}$ & $\begin{array}{l}\text { MI } \\
(<10.57)\end{array}$ & $\begin{array}{l}\text { AUC } \\
\left(<1456 \mathrm{~mm} \mathrm{~h}^{-1}\right)\end{array}$ \\
\hline Healthy & 5 & 5 & 5 & 5 & 5 & 5 \\
\hline Gastro & 33 & 23 & 20 & 17 & 24 & 20 \\
\hline Idiopathic & 28 & 20 & 16 & 15 & 19 & 12 \\
\hline Diabetic & 40 & 27 & 27 & 20 & 33 & 33 \\
\hline$<12 \mathrm{~h}$ & 8 & 8 & 12 & 8 & 21 & 17 \\
\hline$>12 \mathrm{~h}$ & 73 & 47 & 33 & 29 & 29 & 24 \\
\hline
\end{tabular}

$\mathrm{Ct}$, number of contractions; MI, motility index; AUC, area under the pressure curve.

\begin{tabular}{|c|c|c|c|c|c|c|}
\hline & \multicolumn{3}{|c|}{ Gastric window } & \multicolumn{3}{|c|}{ Small bowel window } \\
\hline & $\mathrm{Ct} \mathrm{h}^{-1}$ & $\begin{array}{l}\text { AUC } \\
\left(\mathrm{mmHg} \mathrm{s}^{-1}\right)\end{array}$ & MI & $\mathrm{Ct} \mathrm{h}^{-1}$ & $\begin{array}{l}\text { AUC } \\
\left(\mathrm{mmHg} \mathrm{s}^{-1}\right)\end{array}$ & MI \\
\hline Normal subjects, $n=71$ & 72 & 4789 & 11.83 & 145 & 5182 & 12.78 \\
\hline $\begin{array}{l}\text { Idiopathic gastroparetics, } \\
n=26\end{array}$ & $\begin{array}{c}48 \\
P=0.07\end{array}$ & $\begin{array}{l}4048 \\
P=0.23\end{array}$ & $\begin{array}{r}11.46 \\
P=0.09\end{array}$ & $\begin{array}{c}109 \\
P=0.14\end{array}$ & $\begin{array}{l}4763 \\
P=0.88\end{array}$ & $\begin{array}{r}12.31 \\
P=0.21\end{array}$ \\
\hline $\begin{array}{l}\text { Diabetic gastroparetics } \\
n=16\end{array}$ & $\begin{array}{c}37 \\
P=0.04\end{array}$ & $\begin{array}{l}3032 \\
P=0.26\end{array}$ & $\begin{array}{r}10.84 \\
P=0.03\end{array}$ & $\begin{array}{c}62 \\
P=0.02\end{array}$ & $\begin{array}{l}4325 \\
P=0.55\end{array}$ & $\begin{array}{r}11.6 \\
P=0.04\end{array}$ \\
\hline
\end{tabular}

$\mathrm{Ct}$, number of contractions; MI, motility index; AUC, area under the pressure curve.
Table 2 Percent of patients with significantly abnormal motility parameters for healthy subjects, gastroparetic patients, gastroparetic idiopathic patients, and gastroparetic diabetic patients

Table 3 Median values of motility parameters for healthy subjects vs gastroparetic idiopathic subjects and gastroparetic diabetic subjects 
Table 4 Median values of motility parameters for healthy subjects $v s$ gastroparetic subjects with GET more than $12 \mathrm{~h}$

\begin{tabular}{|c|c|c|c|c|c|c|}
\hline & \multicolumn{3}{|c|}{ Gastric window } & \multicolumn{3}{|c|}{ Small bowel window } \\
\hline & $\mathrm{Ct} \mathrm{h}^{-1}$ & $\begin{array}{l}\text { AUC } \\
\left(\mathrm{mmHg} \mathrm{s}^{-1}\right)\end{array}$ & MI & $\mathrm{Ct} \mathrm{h}^{-1}$ & $\begin{array}{l}\text { AUC } \\
\left(\mathrm{mmHg} \mathrm{s}^{-1}\right)\end{array}$ & MI \\
\hline Normal, $n=71$ & 72 & 4789 & 11.83 & 145 & 5182 & 12.78 \\
\hline Severe gastro, $n=17$ & 23 & 3250 & 9.94 & 61 & 4325 & 11.6 \\
\hline$P$-value & 0.001 & 0.13 & 0.001 & 0.001 & 0.89 & 0.001 \\
\hline
\end{tabular}

$\overline{\mathrm{Ct}}$, number of contractions; MI, motility index; AUC, area under the pressure curve; GET, gastric emptying time.
Seventeen gastroparetics had extremely prolonged GET ( $\geq 12 \mathrm{~h})$. The median Ct of this severe group were found to be even further diminished $(\mathrm{Ct}=23) \mathrm{com}$ pared to the gastroparetic group as a whole $(\mathrm{Ct}=47)$ and healthy subjects $(\mathrm{Ct}=72)$. The median (IQR) contractions, MI and AUC of this group are reported in Table 4 . The medians of healthy subjects compared to mild gastroparetics (GET $<12 \mathrm{~h}$ ) were not significantly different and had large IQR overlaps $(P>0.40)$. The scatter plot in Fig. 2 displays the antral contractile frequency differences among the severe gastroparetics, mild gastroparetics and the healthy group. Seventy three percent of the severe gastroparetics with prolonged ( $>12 \mathrm{~h}$ GET) had gastric frequencies below the $5 \%$ of normal (Table 2).

\section{DISCUSSION}

Gastric emptying studies are routinely conducted when gastroparesis is suspected. Additionally, antroduodenal manometry (ADM) is a useful tool in the evaluation of patients with unexplained upper GI symptoms suggestive of gastroparesis. ${ }^{25}$ The aim of this analysis was to determine if manometry patterns obtained from ingestible free moving capsules currently used for the evaluation of delayed emptying in gastroparesis can also detect differences in pressure profiles between healthy and gastroparetic subjects.

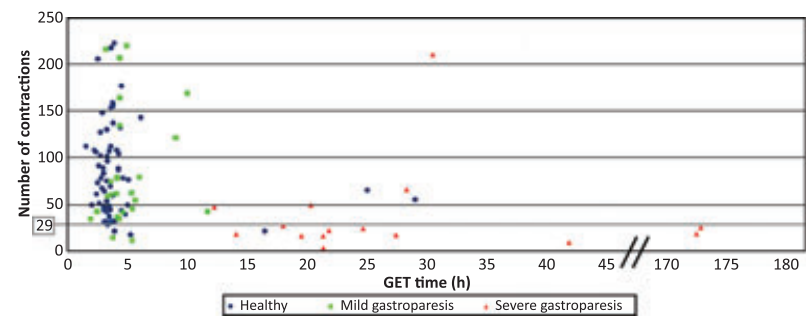

Figure 2 Antral contractile frequencies and corresponding gastric emptying times for healthy subjects, mild gastroparetics (GET $<12 \mathrm{~h}$ ) and severe gastroparetics (GET $>12 \mathrm{~h}$ ). The lower fifth percentile of the healthy population is marked by a line, below $29 \mathrm{Ct} \mathrm{h}^{-1}$ for gastric window.
Unlike catheter-based manometric systems whose location is usually fixed and determined with fluoroscopy, the precise location of the WMC is not known except when it can be inferred briefly by reference to certain physiological $\mathrm{pH}$ changes in the GI tract. Consequently, $1 \mathrm{~h}$ windows before and after GET were chosen for this analysis to assure capture of antral and duodenal pressure patterns. Cassilly et al. reported on manometric profiles recorded simultaneously from this WMC and ADM as part of a study to confirm the emptying of non-digestible objects with phase III migrating motor complexes (MMC). ${ }^{26}$ They noted that pressure patterns recorded by the WMC around the time the capsule emptied the stomach correspond with contractions in the antrum and duodenum recorded by ADM. They further reported that non-digestible objects like the WMC empty from the stomach into the duodenum after the meal has emptied the stomach with high amplitude contractions usually during phase III of the MMC, noting a correlation of $r=0.81$ between the two events. The one pressure sensor configuration of the WMC makes it impossible to detect peristalsis.

Gastric and duodenal motor function was significantly different between healthy subjects and patients with gastroparesis in contractions and MI as recorded by the WMC. ${ }^{27}$ Further, $33 \%$ percent of the overall gastroparetic subjects had gastric motor function below the fifth percentile of the normal population. This prevalence increased to $52 \%$ if the GET of the gastroparetics was $>5 \mathrm{~h}$ and increased to $73 \%$ if the GET was $>12 \mathrm{~h}$. Diabetic gastroparetic patients had significantly different contractile parameters from healthy subjects but this was not the case with idiopathic gastroparetic patients.

Overall gastroparetics had a 35\% reduction in $\mathrm{Ct}$ in both the gastric and small bowel windows compared with healthy subjects. In diabetic subjects with gastroparesis, the $\mathrm{Ct}$ was reduced by $50 \%$. Thumshirn et al., using water-perfused antroduodenojejunal manometry measured during the postprandial period, reported a $70 \%$ reduction in numbers of contractions in 
a group of subjects with confirmed hypomotility. ${ }^{4}$ When our subjects with normal manometric profiles are excluded from our sample similar to Thumshirn's analysis, a nearly identical $75 \%$ reduction in $\mathrm{Ct}$ between groups is observed. They also showed that in the first $2 \mathrm{~h}$ after a meal, the patients with antral hypomotility had a frequency of contractions of $<1$ per minute.

Contraction frequencies in the stomach $1 \mathrm{~h}$ prior to capsule emptying are from 0.75 to 1.8 per minute in healthy subjects. The normal range in the antrum in the fasting state measured by catheter-based manometry is thought to be $2-4$ contractions per minute. ${ }^{4}$ The difference in frequency of contractions detected in normal subjects could be due to pressure measurement technology: fixed catheter vs free-floating capsule. The capsule may pick up fewer contractions than catheterbased manometry due to capsule surfing and movement of the free-floating capsule to gastric locations outside the antrum where fewer lumen occluding contractions may occur. Further, we do not know if catheter-based ADM itself stimulates higher contractions. The observed lower frequency of contractions detected in the stomach could raise a concern about the sensitivity of the device to discriminate between population groups based on pressure profiles. We cannot be certain that the capsule measurement results are as sensitive as ADM results but statistically significant differences between healthy and gastroparetic motor patterns were observed with WMC in a less severe gastroparetic population than routinely studied with ADM. As a result, standards have to be established independently for each technology and validated in further studies in appropriate patients.

The relationship between antral motility recorded by ADM and gastric emptying of solids and liquids in healthy individuals was examined by Camilleri. These authors reported a significant correlation of $60 \%$ between these two physiologic parameters. ${ }^{21}$ This finding emphasizes that correlation between gastric emptying and antral motility does exist, however it is not absolute. In our study, $60 \%$ of subjects identified with gastroparesis by symptoms had a delayed emptying with WMC while one-third of gastroparetic subjects had abnormal motor function. The difference in prevalence of impaired motor function from impaired transit suggest that multiple underlying causes may contribute to delayed transit with the WMC. The motor function was analyzed for the last hour prior to WMC gastric emptying which likely represent predominantly gastric fasted state. The gastric transit results obtained with WMC also provide a measure of fed-state activity as the emptying of the WMC is dependent on the emptying of the meal as noted by Cassilly et al. The dependence of pressure and transit measures obtained with WMC on both fasted and fedstate gastric function may explain the higher sensitivity observed with WMC vs GES which depends on the fed-state activity alone. ${ }^{11}$

The majority of patients with GET greater than $12 \mathrm{~h}$ have gastric frequencies below the fifth percentile of normal subjects. Clinically, patients who still have retained gastric material after an overnight fast $(12 \mathrm{~h}$ between evening meal and AM endoscopy) are considered to have evidence of significant gastric dysmotility. Although using a 12-h cutoff for GET alone may be helpful in indentifying patients with severe gastric dysmotility, some patients may have abnormal transit but normal pressure profiles and vice versa suggesting some independence between these measures. Additionally, GET can be further delayed because of the ingestion of additional meals before WMC emptying from the stomach. Overall, approximately one-third of our gastroparetic patients had significantly reduced gastric pressure contraction frequencies and this is comparable to Soffer's reports of $40 \%$ of patients with severe GI symptoms having upper GI hypomotility characterized by catheter based luminal manometry. ${ }^{28}$ The presence of prolonged emptying along with the low frequency of contractions provides a potential framework for stratifying gastric function into normal, mild and severe categories based on GET and manometric profiles obtained with this WMC.

Gastroparetic patients with milder gastroparesis defined as WMC emptying less of than $12 \mathrm{~h}$ have impaired function but this may not be reflected in their contraction frequencies. This is illustrated in Fig. 2. Mechanisms of dysfunction which may cause severe delay of emptying of an indigestible object may be more related to contractile dysfunction compared to scintigraphic meal emptying which is a related but distinct physiologic process.

Most manometry studies have shown only minor disruptions in small intestinal activity. ${ }^{28}$ However this study clearly shows suppression of duodenal pressure activity suggesting the pathophysiology of gastroparetic symptoms may be due to abnormalities affecting function more globally rather than only the stomach.

The sum of the AUC for the gastric and small bowel analyses windows were not significantly different between gastroparetic and normal subjects. We chose to measure AUC rather than average amplitude of pressure because the AUC provides a more complete assessment of the pressure profile. Thumshirn noted that amplitudes of pressure contractions were also not 
different between groups. ${ }^{4}$ Michoux et al., have shown that gastroparetic subjects have both a lower mean amplitude $(P<0.01)$ and longer length (duration) of contractions $(P<0.01)$ when compared with healthy subjects. ${ }^{29}$ This may explain why there is a statistically significant difference in the Ct but not AUC when comparing healthy to gastroparetic subjects.

There is female predominant gender imbalance in our sample of gastroparetic patients which mirrors the clinical population. The literature has described the effect of gender on gastric emptying and documented both no significant effect and decreased antral contractility in normal women as measured by various techniques. $^{30-32}$ We also observed significant differences between healthy male and female antral contractility. However, further analysis of the data after adjusting for gender imbalance to remove the confounding effect of sex did not alter the outcome of significance testing for the primary motility results reported in Table 1.

The WMC technology is able to record significant differences in pressure profiles between healthy and gastroparetic subjects despite imprecise knowledge of its location and the relatively short analysis windows of a free-floating sensor. A decreased number of antral contractions is a phenomenon which has been detected in a variety of pathological conditions in addition to delayed gastric emptying. This analysis builds the foundation for future studies characterizing abnormal pressure profiles with non-stationary pressure sensing platforms in these conditions. The simultaneous assessment of transit and pressures throughout the entire GI tract in a single non-invasive test may increase the use of manometric profiles to improve our understanding of underlying pathophysiology in GI motility disorders.

\section{FUNDING}

This study was sponsored by The Smart Pill Corporation. Drs Kuo, McCallum, Sitrin, Lackner, Chey, Hasler and Parkman serve as speakers, consultants or advisory board members for The Corporation, and have received research funding from The Smart Pill Corporation. Dr Katz is an advisory board member for The Smart Pill Corporation. Dr Wilding serves as a consultant to The Smart Pill Corporation. Dr Semler is an employee of The Smart Pill Corporation and owns stock in The Smart Pill Corporation.

\section{REFERENCES}

1 Sanders KM, Ordog T, Ward SM. Physiology and pathophysiology of the interstitial cells of Cajal: from bench to bedside. IV. Genetic and animal models of GI motility disorders caused by loss of interstitial cells of Cajal. Am I Physiol Gastrointest Liver Physiol 2002; 282: G747-56.

2 Hasler WL. Gastroparesis: symptoms, evaluation, and treatment. Gastroenterol Clin North Am 2007; 36: 61947.

3 Malagelada JR, Stanghellini V. Manometric evaluation of functional upper gut symptoms. Gastroenterology 1985; 88: 1223-31.

4 Thumshirn M, Bruninga K, Camilleri M. Simplifying the evaluation of postprandial antral motor function in patients with suspected gastroparesis. Am J Gastroenterol 1997; 92: 1496500.

5 Bassotti G, Villanacci V, Mazzocchi A et al. Antroduodenojejunal motor activity in untreated and treated celiac disease patients. I Gastroenterol Hepatol 2008; 23: e23-8.

6 Das K, Sachdeva S, Misra A, Ghoshal UC. Malabsorption syndrome due to various causes is associated with an- troduodenal hypomotility. Indian I Gastroenterol 2006; 25: 58-61.

7 Kusano M, Sekiguchi T, Nishioka T et al. Gastric acid inhibits antral phase III activity in duodenal ulcer patients. Dig Dis Sci 1993; 38: 824-31.

8 Sha W, Pasricha PJ, Chen JD. Correlations among electrogastrogram, gastric dysmotility, and duodenal dysmotility in patients with functional dyspepsia. I Clin Gastroenterol 2009; 43: 716-22.

9 Parkman HP, Hasler WL, Fisher RS. American Gastroenterological Association technical review on the diagnosis and treatment of gastroparesis. Gastroenterology 2004; 127: 1592 622.

10 Camilleri $\mathrm{M}$, Bharucha $\mathrm{AE}$, di Lorenzo C et al. American Neurogastroenterology and Motility Society consensus statement on intraluminal measurement of gastrointestinal and colonic motility in clinical practice. Neurogastroenterol Motil 2008; 20: 1269-82.

11 Kuo B, McCallum RW, Koch KL et al. Comparison of gastric emptying of a nondigestible capsule to a radio-labelled meal in healthy and gastroparetic subjects. Aliment Pharmacol Ther 2008; 27: 186-96.
12 Locke GR, Talley NJ, Weaver AL, Zinsmeister AR. A new questionnaire for gastroesophageal reflux disease. Mayo Clin Proc 1994; 69: 539-47.

13 Tougas G, Eaker EY, Abell TL et al. Assessment of gastric emptying using a low fat meal: establishment of international control values. Am I Gastroenterol 2000; 95: 1456-62.

14 Desipio J, Friedenberg FK, Korimilli A, Richter JE, Parkman HP, Fisher RS. High-resolution solid-state manometry of the antropyloroduodenal region. Neurogastroenterol Motil 2007; 19: 188-95.

15 Faegenburg D, Kryle LS, Kashiwabara $\mathrm{H}$, Doctor NM, Pai P. Intestinal obstruction caused by ingestion of a Heidelberg capsule: report of a case. Am I Gastroenterol 1985; 80: 787-9.

16 Fleischer DE, Leighton JA, Sharma VK, Heigh RI. Video capsule endoscopy (VCE) is useful in the evaluation of unexplained abdominal pain (AP). Gastroenterology 2003; 124: A245-6.

17 Jones BH, Fleischer DE, Sharma VK et al. Yield of repeat wireless video capsule endoscopy in patients with obscure gastrointestinal bleeding. Am J Gastroenterol 2005; 100: 1058-64.

18 Evans DF, Pye G, Bramley R, Clark AG, Dyson TJ, Hardcastle JD. Measurement of gastrointestinal $\mathrm{pH}$ pro- 
files in normal ambulant human subjects. Gut 1988; 29: 1035-41.

19 Mojaverian P, Chan K, Desai A, John V. Gastrointestinal transit of a solid indigestible capsule as measured by radiotelemetry and dual gamma scintigraphy. Pharm Res 1989; 6: 719-24.

20 Mojaverian P, Ferguson RK, Vlasses $\mathrm{PH}$ et al. Estimation of gastric residence time of the Heidelberg capsule in humans: effect of varying food composition. Gastroenterology 1985; 89: 392-7.

21 Camilleri M, Malagelada JR, Brown ML, Becker G, Zinsmeister AR. Relation between antral motility and gastric emptying of solids and liquids in humans. Am I Physiol 1985; 249 : G580-5.

22 Bassotti G, Germani U, Fiorella S, Roselli P, Brunori P, Whitehead WE. Intact colonic motor response to sudden awakening from sleep in patients with chronic idiopathic (slow-transit) constipation. Dis Colon Rectum 1998; 41: 1550-5.
23 Benson MJ, Castillo FD, Wingate DL, Demetrakopoulos J, Spyrou NM. The computer as referee in the analysis of human small bowel motility. Am I Physiol 1993; 264: G645-54.

24 Gielkens HA, Nieuwenhuizen A, Biemond I, Lamers CB, Masclee AA. Interdigestive antroduodenal motility and gastric acid secretion. Aliment Pharmacol Ther 1998; 12: 27-33.

25 Camilleri M. Study of human gastroduodenojejunal motility. Applied physiology in clinical practice. Dig Dis Sci 1993; 38: 785-94.

26 Cassilly D, Kantor S, Knight LC et al. Gastric emptying of a nondigestible solid: assessment with simultaneous SmartPill $\mathrm{pH}$ and pressure capsule, antroduodenal manometry, gastric emptying scintigraphy. Neurogastroenterol Motil 2008; 20: 311-9.

27 Kloetzer L, Kuo B, Semler JR, Smart Pill Trial Group. The discriminative ability of the SmartPill test in defining motility dysfunction in the upper GI tract. Neurogastroenterol Motil 2009; 21(Suppl. 1): 134-5.
28 Soffer E, Thongsawat S. Clinical value of duodenojejunal manometry. Its usefulness in diagnosis and management of patients with gastrointestinal symptoms. Dig Dis Sci 1996; 41: 85963.

29 Michoux N, Lalaude O, Maheu B et al. Postprandial duodenojejunal motility in health and idiopathic severe gastroparesis: from conventional analysis to nonlinear dynamics analysis. Neurogastroenterol Motil 2000; 12: 75-85.

30 Datz FL, Christian PE, Moore J. Gender-related differences in gastric emptying. J Nucl Med 1987; 28: 12047.

31 Knight LC, Parkman HP, Brown KL et al. Delayed gastric emptying and decreased antral contractility in normal premenopausal women compared with men. Am I Gastroenterol 1997; 92: 968-75.

32 Soffer EE, Thongsawat S, Ellerbroek S. Prolonged ambulatory duodenojejunal manometry in humans: normal values and gender effect. Am I Gastroenterol 1998; 93: 1318-23. 